\title{
Research of New Demulsifier in Bohai Oilfield
}

\author{
Ren Yi, Dai Hongcheng, Du Dawei, Cheng Yan, Zhang Liya
}

CNOOC Energy Technology-Drilling \& Production Co., Tianjin, China

Email address:

renyi5@cnooc.com.cn (Ren Yi)

\section{To cite this article:}

Ren Yi, Dai Hongcheng, Du Dawei, Cheng Yan, Zhang Liya. Research of New Demulsifier in Bohai Oilfield. International Journal of Oil, Gas and Coal Engineering. Vol. 9, No. 3, 2021, pp. 42-45. doi: 10.11648/j.ogce.20210903.12

Received: July 7, 2021; Accepted: July 22, 2021; Published: August 2, 2021

\begin{abstract}
The content of asphalt in an EOR oilfield of Bohai is high, reaching more than 30\%, and the content of phenol and naphthenic acid is also high, resulting in high acid value of crude oil. The water content is about $85 \%-95 \%$, and it is in the later stage of mining. Because hydrophobically associating PAM is used as oil displacement agent in the platform, it is difficult to degrade and seriously affects the demulsifier. The oil-water interfacial film formed by polymer, gum and asphalt is very firm, which increases the difficulty of dehydration. There is no ideal product in the selection and application of reverse demulsifier for heavy crude oil with high content of asphalt, high water content and high acid value. In this experiment, triethanolamine was selected as the starting agent from the aspect of branching and introducing nitrogen element, and water-soluble triblock polyether was synthesized according to the ratio of $\mathrm{PO}$ : $\mathrm{EO}$ : $\mathrm{PO}=2: 7: 6$, and then crosslinked with $3 \%$ (relative polyether mass) epichlorohydrin. In the process, the crosslinking temperature was $80^{\circ} \mathrm{C}$, the reaction time was $5 \mathrm{~h}$, and potassium hydroxide solution was used as catalyst. At last, the demulsifier product with good effect of clear water was made, and good effect was obtained in field application.
\end{abstract}

Keywords: Triethanolamine, Demulsifier, Epichlorohydrin, Polyether, Heavy Oil

\section{Introduction}

Chemical demulsifier has become more and more mature after the development of three generation products. Now, it is mainly focused on the methods of head modification, tail changing, bone addition, chain expansion, grafting, cross-linking, and compound [1, 2]. The changing of the head and cross-linking occupy the main means of modification, and the effect is good. In the process of head modification, the starting agent changed from polyols, polyene polyamines to phenol (aldehyde) amine resins. The basic change was to study the targets of multi branches, large molecular weight and heteroatoms $[3,4]$.

\section{Experiment}

The average surface density of this oilfield crude oil is $0.981 \mathrm{~g} / \mathrm{cm}^{3}$, and the average surface viscosity is 1210.8 $\mathrm{MPa} \cdot \mathrm{s}$; The average wax content is $3.8 \%$, the average sulfur content is $0.25 \%$, the asphalt content is $11 \%$, the gum content is $15.2 \%-37 \%$, the acid value is $4.79 \mathrm{mg}-\mathrm{KOH} / \mathrm{g}$, and the API value is about 10 , which is a heavy heavy oil [5]. The existence of natural emulsifier is easy to form w/o film. At the same time, the polymer AP-P4 will be degraded into short chain polyacrylic acid salt and a small amount of quaternary ammonium salt in the formation. On the one hand, the formation water is of $\mathrm{NaHCO}_{3}$ type, which is easy to form hydrolyzed polyacrylic acid monovalent salt, and tends to form $\mathrm{o} / \mathrm{w}$ emulsifier; $\mathrm{On}$ the other hand, quaternary ammonium salt is easy to adsorb on the anionic sandstone surface, which reduces the permeability of crude oil, even more than $60 \%$. The existence of w/o and o/w films makes the system form a complex membrane structure such as o/w/o or $\mathrm{w} / \mathrm{o} / \mathrm{w}$, which increases the difficulty of demulsification [6]. In view of this situation, the following modification methods were carried out: TDI crosslinking [7], star structure [8], acrylation [9], organosilicon modification [10], anion modification [11], phenol amine resin initiator [12], and the effect was not good. Because of the high content and high polarity of colloidal asphaltene in the oilfield, demulsifier with strong polarity should be used. Because amine group is easy to absorb the material with strong polarity, it should contain necessary nitrogen atoms. After analysis, a new demulsifier must be studied by selecting suitable starting agent. In this experiment, triethanolamine was used as the 
starting agent to study a new demulsifier. It not only meets the requirements of introducing nitrogen atoms, but also satisfies the structure of multi branches.

\subsection{Materials and Instruments}

Triethanolamine, $\mathrm{PO}, \mathrm{EO}, \mathrm{KOH}$, Epichlorohydrin (all are industrial grade);

Integrated manifold oil sample, $20-200 \mu \mathrm{L}$ adjustable micro pipette (planland), multiple light scattering instrument (turbiscanlab), and infrared analyzer (Bruker vertex 70).

\subsection{Experiment Method}

(1) Preparation of Demulsifier

Add quantitative triethanolamine and potassium hydroxide into the autoclave, deoxidize with $\mathrm{N}_{2}$, replace for three times, and vacuum. A certain amount of $\mathrm{PO}$ was added at $135 \pm 5^{\circ} \mathrm{C}$, until the reaction was complete; Then control the kettle temperature at $120 \pm 5^{\circ} \mathrm{C}$, a certain amount of EO was added at $5^{\circ} \mathrm{C}$ until the reaction was complete; Raise the temperature to $135 \pm 5^{\circ} \mathrm{C}$, and PO was added into the autoclave. When the reaction is complete, the polyether product is formed;

The polyether product is added into a four port glass bottle, and then a quantitative $\mathrm{KOH}$ solution $(5 \mathrm{~mol} / \mathrm{L})$ is added, which is stirred evenly at $60^{\circ} \mathrm{C}$, and then epichlorohydrin is added into the bottle. After dropping, the temperature is raised to $80^{\circ} \mathrm{C}$ for $5 \mathrm{~h}$. After that, the final product is got, by lowering the temperature.
(2) Demulsification and water-clarifying experiment

Refer to Q/HS 2020-2004 «quality inspection method of crude oil demulsifier» and SY/T 5797-93 «performance evaluation method of oil in water emulsion demulsifier», the effect of demulsifier on SZ36-1cepk manifold oil water sample is investigated.

First, under the simulated field conditions, different types and concentrations of the comprehensive demulsifiers to be evaluated are used to treat the manifold oil and water samples. Then, the size, firmness, generation time, floc floating speed, water color and clarity of the treated flocs at the oil-water interface are observed to determine the application effect of the comprehensive demulsifier. The demulsifier that can quickly produce large floating flocs and is stable, and the water color is clear and transparent. The specific operation steps are as follows:

1) Take the oil and water sample from the manifold, and shake it evenly, then pour it into the dehydrating bottle, and heat it in a constant temperature water bath at $70^{\circ} \mathrm{C}$;

2) After heating for 10 minutes, add the reagent into the dehydrating bottle according to the predetermined concentration (stock solution), and shake it with an oscillator for 50 times to make the reagent mix evenly in the sewage;

3) Immediately observe the sewage state, once the oil and water samples are mixed. Record the test phenomena, and start timing at the same time. After 10 minutes, observe the change of oil and suspended solids [13-15].

\section{Result \& Discussion}

\subsection{Water Clarifying Effect}

Table 1. Comprehensive demulsifier performance evaluation.

\begin{tabular}{|c|c|c|c|c|c|c|c|c|}
\hline \multirow{2}{*}{ reagent } & \multirow{2}{*}{$\begin{array}{l}\text { density } \\
(\mathrm{mg} / \mathrm{L})\end{array}$} & \multirow{2}{*}{ total $(\mu \mathrm{L})$} & \multirow{2}{*}{$\begin{array}{l}\text { Volume liquid } \\
(\mathrm{mL})\end{array}$} & \multirow{2}{*}{$\begin{array}{l}\text { floc floating } \\
\text { velocity }\end{array}$} & \multirow{2}{*}{ floc size } & \multicolumn{3}{|c|}{ water color } \\
\hline & & & & & & $1 \mathrm{~min}$ & $5 \mathrm{~min}$ & $10 \mathrm{~min}$ \\
\hline TEA & 500 & 40 & 80 & fast & mid, small & $\mathrm{B}+$ & A & $\mathrm{A}+$ \\
\hline FP & 500 & 40 & 80 & slow & mid, small & B & A- & A- \\
\hline AP & 500 & 40 & 80 & slow & mid, small & B & $\mathrm{B}+$ & $\mathrm{B}+$ \\
\hline $\mathrm{AE}$ & 500 & 40 & 80 & slow & mid, small & B- & $\mathrm{B}$ & A- \\
\hline SP & 500 & 40 & 80 & slow & mid, small & $\mathrm{B}$ & A- & A- \\
\hline
\end{tabular}

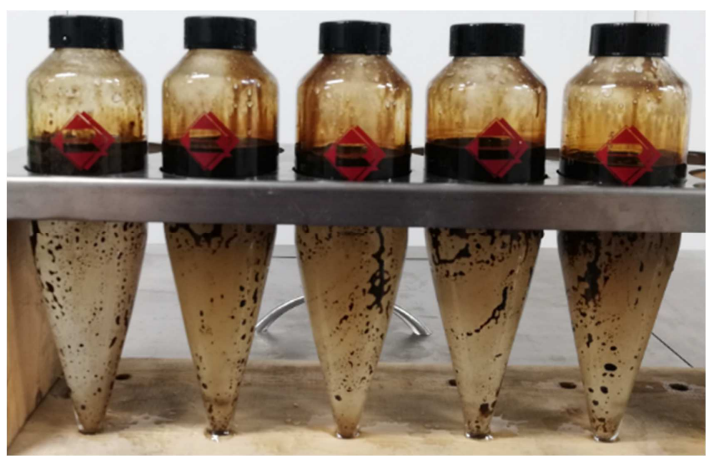

(from left to right: Tea/FP/APAE/SP)

Figure 1. Performance evaluation of comprehensive demulsifier.
It is found that the effect of triethanolamine initiator on water clarifying of platform manifold is the most obvious at the concentration of $500 \mathrm{mg} / \mathrm{L}$. The longer the standing time is, the more obvious the flocculation effect is. Polyene polyamine, phenol amine resin and high carbon alcohol are the second, and triblock polyether is better than diblock polyether at water clearing.

\subsection{Concentration Gradient Experiment}

In order to ensure the authenticity of the reagent effect, the concentration gradient experiment uses the centrifugal bottle to sample directly at the manifold to confirm the effect according to the field conditions. 
Table 2. Performance evaluation of comprehensive demulsifier.

\begin{tabular}{|c|c|c|c|c|c|c|c|c|}
\hline \multirow{2}{*}{ sample } & \multirow{2}{*}{$\begin{array}{l}\text { density } \\
\mathrm{mg} / \mathrm{L}\end{array}$} & \multirow{2}{*}{$\begin{array}{l}\text { total } \\
(\mu \mathrm{L})\end{array}$} & \multirow{2}{*}{$\begin{array}{l}\text { liquid volume } \\
\text { (mL) }\end{array}$} & \multirow{2}{*}{$\begin{array}{l}\text { floc floating } \\
\text { velocity }\end{array}$} & \multirow{2}{*}{ floc size } & \multicolumn{3}{|c|}{ water color } \\
\hline & & & & & & $1 \mathrm{~min}$ & $5 \mathrm{~min}$ & $10 \mathrm{~min}$ \\
\hline $\mathrm{T}-1$ & 200 & 16 & 80 & slower & mid, small & B- & $\mathrm{B}+$ & A- \\
\hline $\mathrm{T}-2$ & 300 & 24 & 80 & slow & mid, small & B & $\mathrm{B}+$ & $\mathrm{A}$ \\
\hline $\mathrm{T}-3$ & 400 & 32 & 80 & fast & mid, small & B & A- & A \\
\hline $\mathrm{T}-4$ & 500 & 40 & 80 & faster & mid, small & $\mathrm{B}+$ & A & $\mathrm{A}+$ \\
\hline $\mathrm{T}-5$ & 600 & 48 & 80 & faster & mid, small & A- & $\mathrm{A}+$ & $\mathrm{A}+$ \\
\hline
\end{tabular}

From this group of experiments, it is found that triethanolamine series takes on obvious effect of water clarifying with the increase of concentration. Considering the effect and economy of the reagents, the water color is bright and the floc state is ideal at the concentration of $500 \mathrm{mg} / \mathrm{L}$.

\subsection{Infra-red Analysis}

The broad and strong absorption peak near $3300 \mathrm{~cm}^{-1}$ is the stretching vibration absorption peak of hydroxyl group, and the stretching vibration absorption peak near $1000-1100 \mathrm{~cm}^{-1}$ is the stretching vibration absorption peak of ether bond. The bending vibration absorption peak of methylene is near $1460 \mathrm{~cm}^{-1}$.

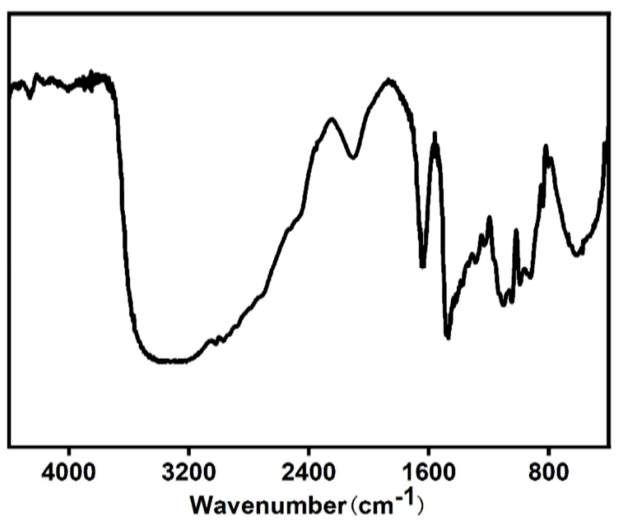

Figure 2. The analysis of infra-red.

\subsection{Backscattering and Transmission Experiment}

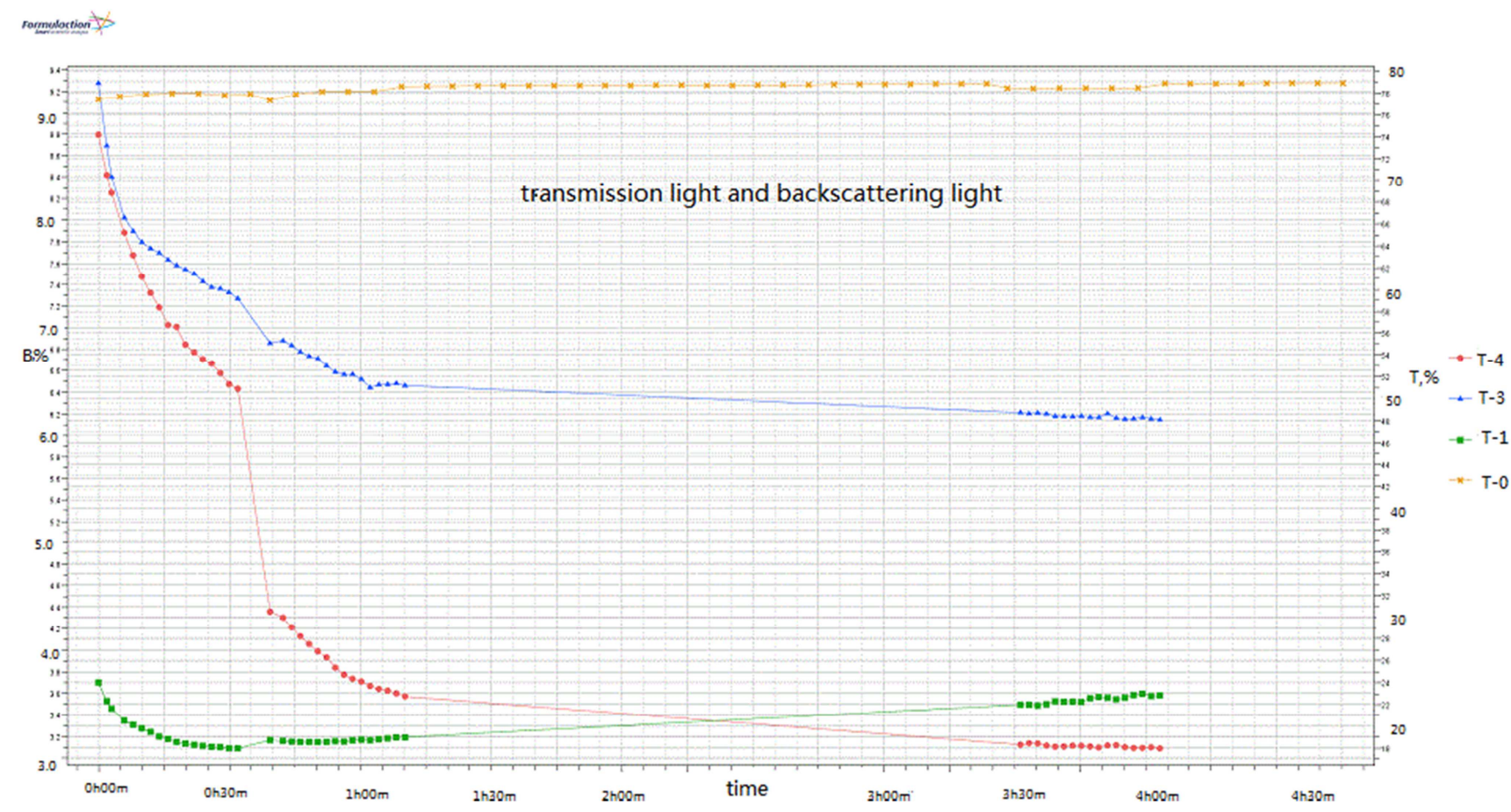

Figure 3. TraNsmission and backscatter images of T series.

It can be seen from the figure that the transmitted light signal of the modified polyether of triethanolamine initiator series changes greatly, and the water quality is greatly improved. The modified polyether of triethanolamine initiator series has good demulsification effect, and has obvious effect on heavy oil with high acid value.

\section{Field Application}

The daily volume of fluid production is about $35000 \mathrm{~m}^{3}$, and the water content is $85 \%$. The crude oil system and water 
system are respectively divided into three-stage processing systems, in which the processing temperature of the primary separator is $75^{\circ} \mathrm{C}$. The polymer content in the produced liquid is about $200 \mathrm{mg} / \mathrm{L}$, and the polymer injection effluent has a serious impact on the heaters at all levels of the crude oil system. Due to the large temperature drop range of heater, long equipment cleaning cycle and no standby equipment during cleaning, the heater is in isolation cleaning all the year round, and the water content of exported crude oil cannot be effectively guaranteed. Due to the influence of polymer flooding, most of the produced liquid of the platform is free water, which is difficult to be treated, and the oil content of the sewage is high, up to nearly $25000 \mathrm{mg} / \mathrm{L}$. The waste oil from the sewage system is simply settled by the waste oil tank, and the waste oil with water content of $40 \%-50 \%$ in the upper part is exported, which increases the water content of the export.

The oil content of wastewater from inclined plate degreaser is as high as $20000 \mathrm{mg} / \mathrm{L}$, the pressure of inclined plate degreaser treatment is high, the amount of waste oil is large, and the polymer is seriously accumulated in the inclined plate degreaser, which affects the treatment effect and capacity. Moreover, the effect of air flotation treatment is not obvious, and the oil removal effect is basically not achieved.

The polymer in the water injection buffer tank is overstocked seriously, which makes it easy to put large polymer into the water injection booster pump after the liquid level is reduced, and it is easy to shut down the booster pump. The oil content in all levels of wastewater exceeds the design value, and the oil content in water injection is high.

Through the field test, the injection concentration of the demulsifier is reduced from $700 \mathrm{mg} / \mathrm{L}$ to $500 \mathrm{mg} / \mathrm{L}$, the outlet water cut is reduced from $12 \%$ to $7 \%$, the oil value of the outlet sewage is reduced to $10000 \mathrm{mg} / \mathrm{L}$, and the water cut of the exported crude oil is significantly reduced.

\section{Conclusion}

(1) According to the evaluation results, in the repeated verification and evaluation of the oil and water samples taken from the process manifold, the effect of comprehensive demulsifier initiated by triethanolamine in the bottle test is relatively ideal, and the longer the action time is, the better the water quality is.

(2) Triethanolamine was used as the starting agent of polyether, the ratio of PO: EO: PO was $2: 7: 6$, then $3 \%$ (relative polyether mass) epichlorohydrin was used as the crosslinking agent, the crosslinking temperature was $80^{\circ} \mathrm{C}$, the reaction time was $5 \mathrm{~h}$, and the hydrogen oxidant solution was used as the catalyst.

\section{References}

[1] MA Lingling. Development of crude oil demulsifier at home and abroad [J]. Chemical Technology Market, 2010, 33 (2): 6-9.

[2] HU Yuguo. The application situation and development trends of demulsifier for crude oil [J]. Jing xi Yu Zhuan Yong Hua Xue Pin, 2000, 5: 13-14.

[3] LIU Liping. Research, application and development of demulsifier for crude oil [J]. Research and Development, 2017, 33 (11): 168-169.

[4] WU Lichun, LIU Songtao, LIU Xuejuan. Current situation of the development of crude oil demulsifier [J]. Detergent \& Cosmetics, 2008, 311 (11): 8-10.

[5] CHENG Yunxia, HE San, MENG Di et al. Study on dehydration technology of heavy oil containing polymer in SZ36-1 oilfield [J]. Petrochemical industry application, 2013, 32 (10): $77-80$.

[6] ZHENG Jilong, SONG Zhixue, CHEN Ping et al. Selection and performance evaluation on foam systems for nitrogen foam flooding in oilfield SZ36-1 [J]. Advances in Fine Petrochemicals, 2013, 14 (4): 34-36.

[7] TAN Guorong, WANG Jinben. Preparation and performance of demulsifier TKQ-2 for crude oil emulsion by polymer flooding [J]. Chemical Engineering of Oil \& Gas, 2008, 37 (1): 56-58.

[8] XU Hui, WEI Qing, ZHANG Lifeng et al. Synthesis and properties of hyperbranched polymer reverse demulsifier [J]. Specialty Petrochemicals, 2019, 36 (3): 46-49.

[9] WANG Zhong, WU Weilong, WANG Mingxian et al. Synthesis and properties of acrylic modified polyether crude oil demusifier [J]. Journal of Shihezi Universithy, 2018, 36 (2): 183-188.

[10] WANG Zhong, LI Danyang. Synthesis and properties of silicone modified polyether OF-125 crude oil demulsifier [J]. Journal of Shihezi Universithy, 2019, 37 (3): 273-279.

[11] WEI Qing, TENG Houkai. Synthesis and performance evaluation of anionic reversed demulsification purifying agent [J]. Industrial Water Treatment, 2019, 39 (8): 52-55.

[12] ZENG Haojian. Study on the synthesis and demulsification of phenol-amine resin block polyether based on bisphenol A [J]. China Surfactant Detergent \& Cosmetics, 2020, 50 (12): 833-841.

[13] Q/HS 2020-2004 «Quality inspection method of crude oil demulsifier» [S]. CNOOC Bohai oil production engineering technical service company, 2004. 10.

[14] SY/T 5797-93 «Performance evaluation method of oil in water emulsion demulsifier» [S]. China National Petroleum Corporation, 1993.9.

[15] SY/T 5796-93 «Evaluation method of flocculant» [S]. China National Petroleum Corporation, 1994. 3. 